\title{
Recommendations for confronting vocational education dropout: a literature review
}

\author{
Antoni Cerda-Navarro ${ }^{1}$, Jaume Sureda-Negre ${ }^{2}$ and Rubén Comas-Forgas ${ }^{3 *}$
}

\author{
${ }^{*}$ Correspondence: \\ rubencomas@uib.es \\ ${ }^{3}$ Department of Applied \\ Pedagogy and Psychology \\ of Education, Balearic Islands \\ University (Spain), Campus \\ UIB Building Anselm Turmeda \\ Office D185, 07122 Palma de \\ Mallorca, Spain \\ Full list of author information \\ is available at the end of the \\ article
}

\begin{abstract}
Despite the importance of the subject of the early school leaving, there are few researches about success and dropout pathways in Vocational Education and Training, while there are many studies centered in other educational levels. This article aims to respond to the following questions: What role do practical recommendations play in research on vocational education dropout? To which specific areas of the educational intervention do these recommendations refer? What specifically are the main practical recommendations for reducing vocational education dropouts? A review of the existing scientific literature has been conducted. A total of 60 documents have been located and analyzed. Results suggests that the main body of recommendations are focused on advising and counseling of students while the recommendations aimed at changing the institutional environment and organization and the teaching staff competences and characteristics are of less concern.
\end{abstract}

Keywords: Dropout, Early school, Leaving, Dropout prevention, Academic engagement

\section{Introduction}

Reducing the high levels of early school leaving is one of the main challenges facing most of European education systems (European Commission 2011; Salva-Mut et al. 2014). Consequently, there is ample research and scientific literature related to this topic, as confirmed in reviews by De Wittea et al. (2013) and by Hovdhaugen et al. (2015). Despite this abundance of literature on dropouts, almost all of it is related to secondary education leaving. Research focusing on vocational education dropout is scarce, specially when compared with the amount of studies focused on secondary education and higher education (Dore and Lüscher 2011; Tanggaard 2013).

Thus, it would be useful to first increase the amount of empirical evidence available regarding dropouts in vocational schools, and second, ensure that this empirical evidence provides useful information to help with making decisions about policies designed to curb the dropout rate in vocational education programs.

The goal of this article is to spread the results of a literature review regarding vocational school dropouts. More concretely, it offers an analysis of the practical recommendations that came out of research projects on how to reduce the number of vocational

(c) The Author(s) 2017. This article is distributed under the terms of the Creative Commons Attribution 4.0 International License (http://creativecommons.org/licenses/by/4.0/), which permits unrestricted use, distribution, and reproduction in any medium, provided you give appropriate credit to the original author(s) and the source, provide a link to the Creative Commons license, and indicate if changes were made. 
education leavers. Early and sustained intervention is a key part of student success and the fight against dropouts because choosing to quit school before graduating is not a snap decision; rather it is the result of a process that develops over many years (Christenson et al. 2001). Continuous empirical study of the interventions that are carried out, the measures taken to confront early school leaving, and the variables that lead to their success, is needed. However, despite the far-reaching effects and significance of this topic on both an individual (students who have dropped out) and a public level, very few published studies have actually focused on the effectiveness of interventions or specific strategies for confronting the problem. A thorough review of early school leaving (Lehr et al. 2003) revealed that research on school dropout has been overwhelmingly predictive or descriptive (mainly analyzing predictive/explicative causes of dropouts) in nature and that most methodologies used to evaluate the effectiveness of interventions have been of low quality and have very little scientific merit or relevance. This was the same conclusion that the USA's General Accounting Office (2002) reached in a report that they published confirming that although there were many federal, state, and local programs in place to prevent school dropouts, during the 2 decades leading up to the study few had been rigorously evaluated. Today, we know much more about who is dropping out of the education system and why they are doing it than we do about the recommendations and intervention strategies to combat this phenomenon that emerge from the empirical analyses. This problem is even more serious with regard to vocational education dropouts. Aside from the lack of careful studies in this area, the analysis and organization of interventions carried out at this level is lackluster at best.

Ultimately, this article aims to respond to the following questions:

(1) What role do practical recommendations play in research on vocational education dropout?

(2) To which specific areas of the educational intervention do these recommendations refer?

(3) What specifically are the main practical recommendations for reducing vocational education dropouts?

\section{Methodology}

In order to answer these questions, we carried out a literature review that focuses on vocational school dropouts. Broadly speaking, this process took the following basic steps: (1) finding relevant documents, (2) selecting and filtering through the documents using clearly defined criteria, and (3) summarizing and analyzing the documents (Fink 2005; Petticrew and Roberts 2006; Littell et al. 2008).

\section{Finding pertinent documents}

\section{First stage: choosing the most relevant databases for the search}

The first step in finding academic works that focused on vocational school dropouts was choosing the databases in which to search for literature. The choice about which sources to 
use was made based on an exhaustiveness criterion. ${ }^{1}$ Special attention was paid to not being limited to only one cultural context, and the search was focused on literature that was subject to some kind of assessment process. Thus, the present paper is centered on two kinds of sources: articles from peer-reviewed journals and doctoral theses. To find them, we consulted major English, French, and Spanish documentary sources (see Table 1).

\section{Second stage: choosing key words and search formulas}

The terms that we used for the literature search (see Table 1) were as follows: "dropout" or "early leaving," along with "vocational education and training" or "VET" for the English-speaking context; "deserción escolar" or "abandono escolar," along "formación profesional" for the Spanish-speaking context; and "abandons," "abandon de études," or "décrochage," along with "formation professionnelle" for the French-speaking context. The choice to use these key words was motivated by an informal initial approach taken by the three members of the research team.

\section{Third stage: putting the search formulas into the databases}

The database queries ${ }^{2}$ were carried out in November and December of 2015, and a time limit was set to search for documents from published before 2014. Flow Chart 1, adapted from Moher et al. (2009), shows how the documents analyzed in the present study were selected.
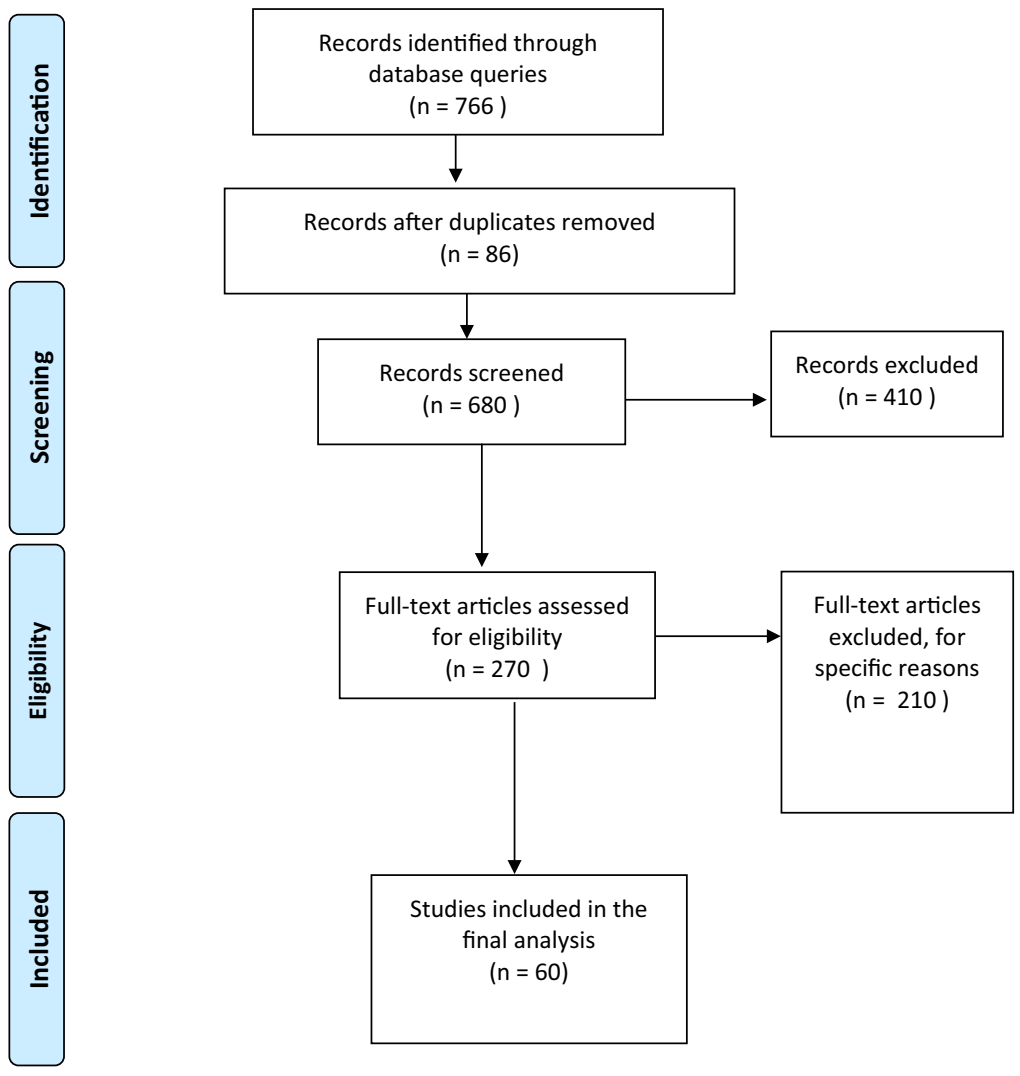

\footnotetext{
1 The exhaustiveness criterion is understood to be "the relevance of the evidence to the review. This should lead to an overall judgment of the external validity of the review. Are the studies identified sufficient to address all of the objectives of the review?" (Higgins and Green 2011, p 84).

2 The researchers themselves carried out all of the databases queries except for the query of Dissertation Abstracts International. This database could not be accessed directly; rather a request for the search to be carried out had to be made to via the Document Resources Office of a university.
} 
Table 1 Databases queried, search strategy used for each one, and results

\begin{tabular}{|c|c|c|c|}
\hline Database & Search strategy & Results & Search date \\
\hline \multirow[t]{4}{*}{ ERIC } & title:drop-out OR title:leave AND title:vocational & 12 & $4 / 11 / 2015$ \\
\hline & idem peer reviewed & 8 & $5 / 11 / 2015$ \\
\hline & title:"early leaving" AND title:VET & 1 & $5 / 11 / 2015$ \\
\hline & title:"early leaving" AND title:Vocational & 1 & $5 / 11 / 2015$ \\
\hline \multirow[t]{3}{*}{ SCOPUS } & TITLE (dropou*) OR TITLE (leav*) AND TITLE (vocational) & 28 & $4 / 11 / 2015$ \\
\hline & TITLE ("early leaving" OR "dropout") AND TITLE (vet) & 1 & $5 / 11 / 2015$ \\
\hline & TITLE (early leaving) AND TITLE (vocational) & 2 & $5 / 11 / 2015$ \\
\hline \multirow[t]{3}{*}{ WEB OF SCIENCE } & $\mathrm{TI}=($ dropou* OR leaving $) \mathrm{ANDTI}=($ vocational $)$ & 22 & $4 / 11 / 2015$ \\
\hline & $\begin{array}{l}\text { The same, but limiting the years from } 1980 \text { to } 2014 \text { and } \\
\text { including only articles } \\
\text { Search: TI = (dropou* OR leaving) ANDTI = (vocational) } \\
\text { Time period: Up to } 2014 \text { (included). Indexes: SCI-EXPANDED, } \\
\text { SSCI, AandHCI, CPCI-S, CPCI-SSH, CCR-EXPANDED, IC. }\end{array}$ & 15 & $5 / 11 / 2015$ \\
\hline & Title: (early leaving) AND Title: (vocational) & 2 & $5 / 11 / 2015$ \\
\hline ISOC & $\begin{array}{l}\text { TI"Abandono escolar" OR "abandono" OR "deserción" AND TI } \\
\text { "formación profesional" }\end{array}$ & 1 & \\
\hline \multirow[t]{2}{*}{ REDALYC } & "Abandono escolar"“"deserción"Title AND "profesional" & 67 & $5 / 11 / 2015$ \\
\hline & "abandono"Title AND"profesional"Title & 2 & $5 / 11 / 2015$ \\
\hline \multirow[t]{2}{*}{ DIALNET } & "Abandono escolar" AND "formación profesional" & 8 & $4 / 11 / 2015$ \\
\hline & "deserción escolar" AND "formación profesional" & 0 & $4 / 11 / 2015$ \\
\hline \multirow[t]{3}{*}{ FRANCIS } & TI dropou* ORTI leaving AND TI vocational & 212 & 4/11/2015 \\
\hline & TI décrochage scolaire AND TX professionnel & 4 & $5 / 11 / 2015$ \\
\hline & "Professionnel" all text fields AND "Abandon" title & 12 & $11 / 11 / 2015$ \\
\hline Bibliothèque Diderot & Title Décrochage and professionnel & 2 & $5 / 11 / 2015$ \\
\hline SUDOC & (Title words) Décrochage scolaire AND professionnel & 2 & $5 / 11 / 2015$ \\
\hline SCIENCEDIRECT & TITLE(dropout*) and TITLE(vocational). & 5 & $5 / 11 / 2015$ \\
\hline Recolecta & Title="Abandono"AND Title="profesional" & 3 & $5 / 11 / 2015$ \\
\hline \multirow[t]{2}{*}{ REDINET } & $\begin{array}{l}\text { Ámbito "En todo Redined" [within all of Redinet]. "abandono } \\
\text { escolar" AND Title"profesional" }\end{array}$ & 1 & $5 / 11 / 2015$ \\
\hline & $\begin{array}{l}\text { Ámbito "En todo Redined" [within all of Redinet]. "deserción" } \\
\text { AND Title "profesional" }\end{array}$ & 4 & $5 / 11 / 2015$ \\
\hline JSTOR & $\begin{array}{l}\text { (ti:dropout OR tb:dropout OR ti:engagement OR } \\
\text { tb:engagement) AND (ti:vocational OR tb:vocational) }\end{array}$ & 3 & $5 / 11 / 2015$ \\
\hline EERA RED (VETNET) & "DROPOUT"AND"VOCATIONAL" & 5 & $12 / 11 / 2015$ \\
\hline \multirow[t]{2}{*}{ Portal education.gouv.fr } & Abandons en contenido & 94 & $12 / 11 / 2015$ \\
\hline & Abandon des études & 57 & $12 / 11 / 2015$ \\
\hline Ingentaconnect & Drop-out and vocational in Article title, keywords or abstract & 33 & $12 / 11 / 2015$ \\
\hline \multirow[t]{3}{*}{ IRESIE } & $\begin{array}{l}\text { WTI_-Title }=(" \text { abandono escolar") AND WTI-Title = profe- } \\
\text { sional }\end{array}$ & 1 & $14 / 11 / 2015$ \\
\hline & $\begin{array}{l}\text { WTI_Title }=(" \text { abandono escolar") AND WTI-Title }=\text { profe- } \\
\text { sional }\end{array}$ & 1 & $14 / 11 / 2015$ \\
\hline & Title "deserción escolar" and "profesional" abstract & 1 & $14 / 11 / 2015$ \\
\hline \multirow[t]{2}{*}{ Narcis } & "drop-outs" and "vocational" & 2 & $17 / 11 / 2015$ \\
\hline & "engagement" and "vocational" & 17 & $17 / 11 / 2015$ \\
\hline \multirow[t]{2}{*}{ Taylor and Francis Online } & "drop-out" title AND "vocational education" keywords & 6 & $18 / 11 / 2015$ \\
\hline & "engagement" title AND "vocational education" keywords & 3 & $18 / 11 / 2015$ \\
\hline $\begin{array}{l}\text { Dissertation Abstracts } \\
\text { International (Proquest) }\end{array}$ & Drop-out AND vocational OR VET & 46 & $19 / 11 / 2015$ \\
\hline ScienceResearch & Full Text: vocational/Title: dropout & 46 & $6 / 12 / 2015$ \\
\hline \multirow[t]{2}{*}{ VETBib (CEDEFOP) } & Title like 'Early leaving' AND Title like 'vocational' & 25 & 9/12/2015 \\
\hline & Title like 'dropout' AND Title like 'vocational' & 8 & 9/12/2015 \\
\hline TOTAL & & 766 & $9 / 12 / 2015$ \\
\hline
\end{tabular}




\section{Filtering and selecting documents}

Once the documents were located in the various databases, we proceeded to eliminate duplicates and those that were not relevant to the objectives of our study. This filtering took place between January and April of 2016, and was carried out according to the following basic criteria:

(a) Firstly, only empirical studies were considered.

(b) Secondly, only research focused on vocational education leaving was considered. However, given that this kind of education falls under the classification of secondary education in some countries, studies that focused on vocational training programs were included.

(c) Thirdly, studies that focused exclusively on students which physical, psychological, or serious learning disabilities were excluded. However, some studies were included that focused on populations in difficult socioeconomic situations or whose profiles showed that they were prone to conflicts.

(d) Finally, only scholarly works that had undergone a peer-review process were considered. Thus the search for documents was limited to articles published in peerreviewed journals and doctoral theses. Other texts like book chapters, minutes of conferences, and research reports were excluded as we could not ensure that they met the established criteria.

After applying these filters, the search yielded 60 documents to be considered in the analysis stage: 37 scholarly articles and 23 theses. For more detailed information, (annex, Table 3) compares the texts that were included and provides a description of their main characteristics.

\section{Analysis and summary of documents}

First phase: identifying the pieces of text to be analyzed (selection of verbatims)

The first phase of the analysis consisted of a round in which each member of the team carried out two in-depth readings (six readings in total) of the 60 documents included in the analysis. This was done in order to identify the practical recommendations present in each text. Then, we compiled, organized, and came to a consensus regarding the recommendations that were gathered and created a single working paper to simplify the analysis. This phase took place during May and June 2016.

\section{Second phase: categorizing the data}

The second phase of the analysis involved creating an initial outline of the categories that would be used to classify and group the recommendations that were found. For this classification, inductive criteria (Mejía Navarrete 2011) and open coding (Strauss 1987; Strauss and Corbin 1998) were used: the classification categories were not the result of a restrictive a priori theoretical framework but rather several readings of the data. We followed the indications of Taylor and Bodgan (1987) throughout this process. They mentioned, among other things, the usefulness of repeatedly going over the data. Thus, during this phase, we used a process of triangulation to repeatedly include, modify, and eliminate different categories for the analysis. Throughout successive rounds we worked 
on refining the analysis categories that we created and justified based on the working paper. The final categories used for the analysis were obtained after three rounds. This phase took place between July 2016, and October 2016.

Third phase: grouping the recommendations based on similar ideas and their descriptions

Once the verbatims (text fragments) were classified and ordered into different categories, we honed the categorization (between October and December 2016). To do this, we followed an inductive process to group the verbatims that expressed similar ideas or recommendations into subcategories within the already defined categories from the previous phase. This was done to make it easier to analyze and describe them. The results of this analysis are shown in the following section.

It should be pointed out that some initial verbatim were rejected within the analysis because of dealing with very specific issues in the countries where the research was carried out. Because the article did not intend to search for specific country or geographical patterns, those were not searched for and instead of analyzing patterns we looked for structural and general common elements throughout the literature revised.

\section{Results}

What role do practical recommendations play in research on vocational education dropout?

As a starting point, it should be noted that in 7 of the 37 articles $(18.9 \%)$ and in 1 of the 23 theses (4.3\%) analyzed, no explicit recommendations regarding vocational school dropouts could be found. This means that the majority of the empirical studies (86.9\%) on this topic provided some kind of recommendation(s) or measure(s) intended to address the problem. As a result of the first phase of the analysis (described in the previous section), 199 text fragments, or verbatims, were identified as referring to practical recommendations for reducing the number of dropouts in vocational education programs. They came from 52 of the documents that were analyzed.

Worth mentioning here is that some documents provided recommendations in sections specifically designed for such a purpose, while others gave recommendations implicitly in the "Conclusion" section or in the discussion of the results. Furthermore, these verbatims often appeared as paragraphs expressing various ideas or recommendations, instead of being short unambiguous sentences. As a result, one verbatim does not necessarily equate to just one recommendation.

\section{To which specific areas of the educational intervention do these recommendations refer?}

As a result of the second phase of the analysis, we proceeded to organize the verbatims, into five overall categories referencing the different specific areas of educational interventions. These categories are listed in Table 2:

The category with the most recommendations is the one that deals with the advising and counseling of students (53 verbatims). The categories related to the programs themselves and teaching methodologies each had 49 verbatims. The category that grouped recommendations having to do with the center, and organizational and participative aspects included 40 verbatims, and the category referring to the teaching staff had 19. 
Table 2 Categories used for organizing recommendations

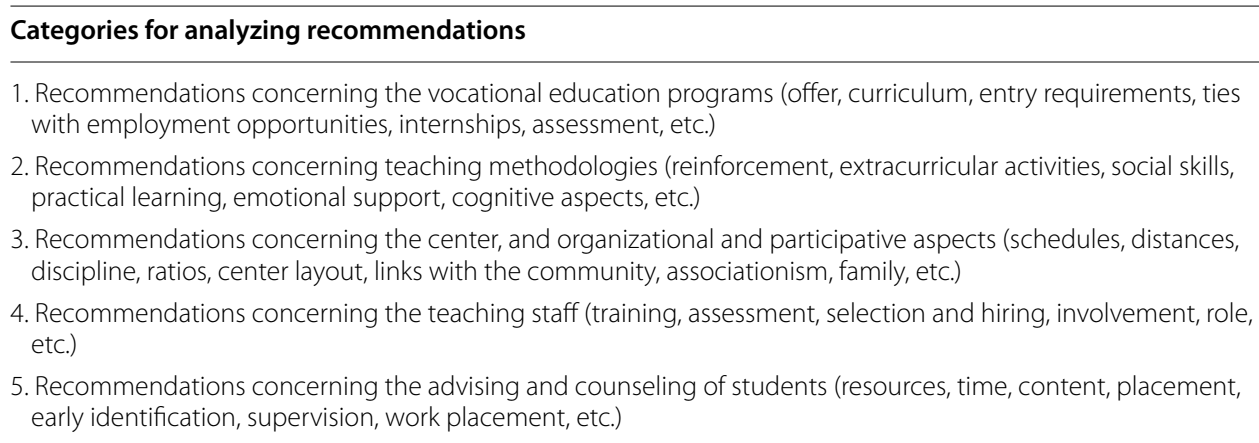

However, it should be noted that, as previously explained, the text fragments (verbatims) included in the analysis were often found in paragraphs that expressed various ideas or recommendations. As a result of this, some verbatims were included in more than one category or even repeated within the same category. Thus, the number of verbatims cited in each one of the categories does not coincide with the total number of verbatims included in the analysis.

\section{What specific recommendations for curbing dropouts in vocational education programs came out of the studies that were analyzed?}

This question responds to the third part of our methodology. Hereafter, we describe and expand upon the analyses of the recommendations found in each of the categories and subcategories presented in Table 2.

Recommendations concerning the vocational education programs (offer, curriculum, entry requirements, ties with employment opportunities, internships, assessment, etc.)

One set of recommendations found in this category refers to the education that is offered: suggesting that it would be helpful to update education programs (Tien, 1978) and reassess programs that already exist (Redfering and Cook, 1980). Other recommendations have to do with expanding the academic offer (Redfering and Cook, 1980) and creating innovative programs (Thaniel, 1989). In this way, some of the recommendations that were found address the need to increase funding not only for human resources (Thaniel, 1989) but also for more advanced technological infrastructures (Mohd Kamalludeen, 2012).

Another set of recommendations focuses on the need to better adapt the education to the abilities, needs, and interests of the students (Wade, 1974). In this regard, it would be helpful to introduce programs and curricula in which the students can specialize (Aguirre, 1991) by completing a series of courses within an area of interest while ignoring minimum graduation requirements (Mohd Kamalludeen, 2012) and preparing students for the professional world or higher levels or education (Raffington, 2012). To this effect, we find it necessary to bolster vocational education, from its early stages (Aguirre, 1991; Rahona, 2012), via a differentiation of curricula or the creation of alternative ones (Tien, 1978). With respect to adapting vocational education programs to students' needs, one of the more interesting recommendations suggests that it would be useful to carry out 
programs in a language different from the official one so as to prevent immigrant populations from being those who most drop out (Aguirre, 1991). ${ }^{3}$

Related to the previous point, there is another series of recommendations that focus on the need to review the programs' entry requirements (Karling, 2008) in order not to leave out students that could potentially benefit from this kind of education (Langley, 1993). In this way, it would not be necessary for students to have graduated from primary or secondary school in order to take advantage of vocational schooling and benefit from its positive effects (Redfering and Cook, 1980). Also recommended are the development of assessment tools tied to the professional objectives of the programs as well as a description of the requirements and abilities needed to access the program (Grønborg, 2013). Furthermore, measures designed to reduce potential socioeconomic, transportrelated, or family-based obstacles to accessing education programs must not be ignored (Wade, 1974; Karling, 2008).

Another set of recommendations that were analyzed suggest that it would be helpful to establish ties between vocational training and employers. To this end, a more indepth analysis of the relationship between what is offered and the work skills that are demanded would be helpful, as would an analysis of the most effective ways of communicating what these skills are so as to include them in vocational education programs (Wilms and Hansell, 1982). In this respect, it is also recommended that an effort be made to promote, publicize, and increase the prestige associated with vocational education both among businesses and the public in general (Thaniel, 1989). Another recommendation is to increase the social visibility of the skills and abilities that program graduates acquire (Cummins, 1973).

An important set of recommendations has to do with the need to include, in the vocational training programs, practical work experience that is in line with students' professional objectives (Diamond, 2007) and that has value to them (Thaniel, 1989). This highlights the importance of field work (Azzarano, 1981) and applying what has been learned in the real world (Haight, 2012). To this effect, some authors recommend promoting and developing training programs that foster close relationships between the training and real work, such as work-study programs (Redfering and Cook, 1989), Career Academy ${ }^{4}$ models (Haick, 2010; Kwong, 2010), work-based mentoring ${ }^{5}$ (Raffington, 2012), and dual vocational training ${ }^{6}$ (Mohd Kamalludeen, 2012). In this respect, students with families can benefit from the salaries they receive from their internships while they

\footnotetext{
${ }^{3}$ Aguirre's (1991) study focused on a center in California where 91\% of the students were of Latin American descent. As a result, a series of problems arose regarding both students' and families' limited capabilities in the official language of the education system.

4 Haick's (2010) study, in accordance with the National Academy Foundation (2009), defines Career Academy programs as a schools within schools which offer classes that are reduced in size and have curricula designed with career- and technical-education in mind. Furthermore, they create synergies between employers, the community, and schools. Kwong's (2010) study suggests that Career Academies, an idea which was introduced in the 1970s, have the objective of keeping students in school by offering them professional training and preparing them for skilled positions in the labor market. As it has evolved, this model has incorporated integrated professional academic curricula, a small learning-community structure, and alliances with local businesses in order to help students with their transition to the workplace.

5 Raffington's (2012) study refers to "career mentoring" or "work-based mentoring" as a learning system based on work in which students are matched with an adult worker who gives them direction and guidance with regards to workforce experience.

${ }^{6}$ Mohd Kamalludeen's (2012) study refers to dual vocational training curricula in which students are prepared on both an academic and professional level and special emphasis is put on practical learning in the workplace.
} 
are being trained (Taş, Bora, Selvitopu, and Demirkaya, 2013). It is also important to note that alternative programs should provide a solid academic base in order not to produce the unwanted effect of converting them into elements that reinforce social exclusion (Bruin and Ohna, 2013).

The largest set of recommendations in this category refers to the need to establish periodic assessment systems for the training programs (Cummins, 1973) as well as permanent and updated data registries (Raffington, 2012) that track success and impact, costs and benefits (Cummins, 1973), and areas where improvements can be made (Klinger, 1973; Portis, 20137 Marín, Carmona, and Reche, 2014 ${ }^{8}$ ). Along the same line, Thaniel (1989) recommends that politicians, and those in charge of making decisions regarding education, consider the results of these assessments and studies when it comes time to making policy decisions and designing curricula.

To carry out these program assessments, it is necessary to define what is important to measure and how to do it (Portis, 2013). In this regard, for example, it is important to redefine the idea of school dropout to include young people who do not graduate but who do acquire vocational skills (Klinger, 1973), do away with the idea of dropout that includes students who change study programs or education centers (Klinger, 1973), and see whether or not those who have dropped out of vocational programs later come back to either formal or informal education programs (Prawatrungruang, 2002).

Other recommendations highlight the need to create assessment tools related to the professional objectives of vocational programs (Grønborg, 2013; Portis, 2013). However, one recommendation suggests that these assessments should not be based on objectives so as to put the focus of the analysis on the unplanned results of the programs (Langley, 1993).

Along the same line, some recommend including information from all of the actors involved. This means considering the perspectives of dropout students as well as students who finish study programs, and of course teachers, people working at the education center, and employers (Cummins, 1973; Masdonati, Lamamra, and Jordan, 2010 Raffington, 2012).

Many authors recommend including follow-up assessments after students finish vocational programs in order to measure their impact over the medium and long terms (Cummins, 1973; Wade, 1974; Cadena, 2013; Portis, 2013; Marín, Carmona, and Reche, 2014).

\section{Recommendations concerning teaching methodologies (reinforcement, extracurricular activities, social skills, practical learning, emotional support, cognitive aspects, etc.)}

Given that some of the students in vocational education programs have low levels of proficiency in basic learning abilities (i.e., reading and writing), some recommendations

\footnotetext{
${ }^{7}$ In his study, Portis (2013) mentions the Dropout Recovery Programs that are a part of the Oklahoma Department of Career and Technology Education. They provide students who drop out of school with the opportunity to enroll again in order to get an official certificate and take specific vocational training courses.

8 The study by Marín, Carmona, and Reche (2014) makes reference to Initial Professional Qualification Programs (in Spanish, Programas de Cualificación Profesional Inicial), new measures in Spain dedicated to the educational, social, and occupational inclusion of students who leave mandatory schooling without having graduated.

9 The study by Masdonati, Lamamra, and Jordan (2010) was carried out in Switzerland, where vocational training programs have a dual focus: from the very first day students gain experience in businesses and real working environments with tutors who are workers, not teachers.
} 
deal with the need to offer mandatory courses to help students compensate for their lack of these basic skills (Tien, 1978; Azzarano, 1981; McKay, 2005). It should also be noted that Azzarano (1981) recommends increasing efforts in previous educational stages to alleviate these shortcomings.

Cadena (2013) recommends identifying and using the ideal learning style for each student and notes that students at risk of dropping out have a tendency to improve when their individual needs are addressed and the education is tailored for them to be able to handle the tasks associated with learning. Similarly, Diamond (2007) suggests that competency-based education and individualized teaching increase engagement and that teachers' styles of explaining and their ability to present information in simple ways that are understandable to students help to prevent student dropouts.

Other recommendations involve including content that focuses on students' social and relational abilities (Mohd Kamalludeen, 2012), as both professional and academic success rely, at least partly, on these kinds of abilities (Dykeman, 1977; Diamond, 2007). Along this line, Dykeman (1977) and Tien (1978) recommend the use of interactive activities, such as discussion groups or other activities that help to improve communicative abilities which can in turn lead to increased problem solving skills, as Frey, Balzer, and Ruppert (2014) suggest. In this way, the importance of general cultural competencies is highlighted ${ }^{10}$ as well as students' previous knowledge in the learning process (Hui and Cheung, 2014). Along the same line, another recommendation suggests the usefulness of including aspects from the humanities and social sciences in all vocational education programs, even if they have a technical focus (Tien, 1978).

Another set of recommendations deals with the benefit of promoting practical or applied learning (Thaniel, 1989; Diamond, 2007; Haight, 2012; Raffington, 2012), such as the use of field experiences or audiovisual resources to stimulate students (Azzarano, 1981). Similarly, it would be useful to foment teamwork and collaboration between the teachers of different professional and academic curricula (Tien, 1978; Aguirre, 1991) in order to develop common teaching practices in which students can apply both theoretical and practical knowledge (Mohd Kamalludeen, 2012).

We also found a set of recommendations in the literature that highlighted the advantages of emphasizing the handling of socio-emotional aspects. Sometimes, these were suggested to be even more important than academic ones (Diamond, 2007; Fanoiki, 2014). This would involve teachers giving more emotional support to students and giving extra attention to the factors associated with a risk of school leaving, and thus compensating, in some way, for possible shortcomings in other areas (Cadena, 2013). More specifically, it is recommended that both teachers and guidance counselors spend more time with students, listening and paying more attention to their school and family experiences (Jonker, 2006; Diamond, 2007; Cadena, 2013). Ultimately, it involves improving the quality of teacher-student relationships (Jahnukainen and Helander, 2007; Jonasson, 2012) and building an environment that encourages support and learning processes (Cadena, 2013) and that emotionally and intellectually involves students in their academic environments (Diamond, 2007; Elffers, Oort, and Karsten, 2012; Cadena, 2013).

\footnotetext{
10 The study by Hui and Cheung (2014) uses the concept of "cultural literacy" to refer to a set of personal competencies that go beyond professional ones. In this way, they are referring to students' social abilities, the manner in which they interact with people, their worldview, their character, their ethics, their values, their sense of responsibility, etc.
} 
Another series of proposals are focused on the benefits of working on the range of cognitive and attitudinal factors that students have. To this end, it is recommended that teachers develop various strategies for motivating students in order to help them overcome the academic challenges that they face (Jonker, 2006; Raffington, 2012; Cadena, 2013; Hui and Cheung, 2014) as well as providing them with experiences that foster their self-esteem (Dykeman, 1977) and both their professional and academic expectations (Dykeman, 1977; Azzarano, 1981), as students with professional goals and expectations for the future tend to develop the attitudinal factors necessary for being academically successful (Dykeman, 1977) and more involved in their own learning process (Kwong, 2010).

The last subcategory of recommendations has to do with the benefit of extracurricular activities. It is recommended that both extracurricular and co-curricular activities be incorporated into programs in order to stimulate students' interests and talents (Mohd Kamalludeen, 2012). They could include workshops, seminars (Cummins, 1973), or conferences (Tien, 1978).

\section{Recommendations concerning the center, and organizational and participative aspects (schedules, distances, discipline, ratios, center layout, links with the community, associationism, family, etc.)}

This category includes the set of recommendations that we compiled regarding improving various logistical and organizational aspects. In this respect, it is important to review and adapt class schedules so that they are more flexible for students (Wade, 1974), but also so that teachers can have a normal work schedule (Haick, 2010). The need to determine and implement the timetables that are most beneficial, whether they are full- or part-time, is equally important (Karling, 2008).

Another recommendation is to reduce the distance that students have to travel to attend courses by building multidistrict vocational education centers (Wade, 1974) or resolving transport problems that students might face when going to and coming from the centers (Karling, 2008).

Some recommendations suggest that it would be useful to review the disciplinary systems in centers to ensure that they are not overly punitive (Tien, 1978) or strict (Prawatrungruan, 2002) in order to do away with the proven link between expulsions and other penalties, and dropout (Thaniel, 1989).

Other recommendations refer to the usefulness of reducing class sizes and the student-to-teacher ratio, especially in programs for students with difficulties. This would allow for the teaching staff to provide students with more support materials and personalized attention (Wade, 1974). To this end, Thaniel (1989) and Haick $(2010)^{11}$ discuss the benefits of small learning communities, while other authors suggest that they have a limited effect if they are not accompanied by changes in teaching practices (Kwong, 2010).

One of the most noteworthy recommendations suggests the creation of management teams that develop strategic plans for education centers in order to help students at risk

\footnotetext{
${ }^{11}$ Haick's (2010) study refers to the Career Academy model which offers vocational training in small classes and aims to develop collaborative synergies between employers, the community, and the centers. According to the author, small communities offer students more personalized learning experiences and allow them to build closer relationships with their peers and teachers, which helps them progress academically.
} 
of dropping out (Cadena, 2013). Likewise, it is recommended that these teams are given ample time to meet, develop, and discuss their plans as well as how to monitor the progress of students, assess the effectiveness of the plan, and modify it if necessary (Cadena, 2013). Other recommendations along this line have to do with promoting collaboration and teamwork between teachers at different levels and across curricula (Cadena, 2013; Aguirre, 1991; Tien, 1978; Mohd Kamalludeen, 2012).

Similar to this point, another set of recommendations highlights the benefit of creating dropout commissions (Taş, Bora, Selvitopu, and Demirkaya, 2013) or workgroups for reducing absenteeism (Azzarano, 1981) and promoting student attendance (Tien, 1978). In these cases, the recommendations suggest the need to involve various agents, such as the guidance and psychology departments (Taş, Bora, Selvitopu, and Demirkaya, 2013), centers' management and teaching staff (Tien, 1978; Cadena, 2013), families (Wade, 1974; Aguirre, 1991), and even the community in which the center is located (Azzarano, 1981).

Likewise, some recommendations refer to the utility of having centers establish various links (through directors, teachers, and counselors) with the community and other levels of education. Co-curricular and extracurricular activities can develop as a result of these links, and beyond assessments and exams, they can stimulate students' interests or reveal hidden talents (Tien, 1978; Kamalludeen, 2012). Along this line, Raffington (2012) suggests organizing activities such as, job fairs, career days, field trips, and seminars. It is also suggested that the education centers provide students with internship or work placement opportunities in the communities in which they are located or in nearby areas (Raffington, 2012).

Another set of recommendations that we found refer to the benefit of promoting student participation and associationism (Klinger, 1973). With respect to this point, Wade (1974) urges fostering student associationism in centers, and Azzarano (1981) recommends introducing, implementing, and expanding organizations for young professionals as a part of vocational education programs. We also found recommendations referring to the need to increase student participation in committees and/or bodies representing the education center (Tien, 1978).

Given that school leaving is a phenomenon that can be influenced by factors that are unrelated to the school, a series of recommendations explicitly deal with the need to involve families in their children's academic lives (Wade, 1974; Aguirre, 1991; Fanoiki, 2014). Recommendations suggest applying or strengthening strategies that encourage parents to be more participative in the education centers, organizing activities that involve parents (e.g., a day to visit the school), and including them in extracurricular activities such as field trips or fairs (Aguirre, 1991). It is also recommended that parents be given work rooms in centers where they can meet and be included in the decision making process that centers go through (Aguirre, 1991).

Further recommendations have to do with the need to improve and strengthen academic and professional guidance services directed at parents. Here, workshops for parents designed to give them information about school dropout (Fanoiki, 2014; Thaniel, 1989), the objectives of and requirements for graduating, planning the study possibilities that their children have (Aguirre, 1991), employment opportunities and associated salaries (Colding, 2006), etc. 
Recommendations concerning the teaching staff (training, assessment, selection and hiring, involvement, role, etc.)

Some of the recommendations that we analyzed refer to the need to organize training programs for teachers (Klinger, 1973) in order to improve their abilities when it comes to teaching and communicating (Tien, 1978; Frey, Balzer, and Ruppert, 2014). In this regard, the way in which teachers explain class material and their ability to provide clear and simple explanations to their students are important (Diamond, 2007). One recommendation emphasizes the need for programs to include components related to conflict management and resolution (Frey, Balzer, and Ruppert, 2014), as well as for dealing with associationism, in order to improve student involvement in extracurricular activities offered by the center (Wade, 1974). Other recommendations suggest that it would be useful to provide the teaching staff with training that would allow them to better understand the cultural and linguistic diversity present in the student body (Aguirre, 1991) and how this diversity relates to school dropout (Fanoiki, 2014). It is also recommended that both teachers and those working in the education centers enroll in language courses so that they can better understand students and their families (Aguirre, 1991).

Another set of recommendations deals with the usefulness of carrying out periodic assessments of teachers' training and the actual impact that it has, e.g., by comparing the results achieved by teaching staff that receives training versus the results obtained by those who do not receive training (Klinger, 1973). Along this line, it is recommended that those teaching methods and practices which have been proven to be effective be identified and ranked. Associated competencies should then be documented and shared with teachers (Klinger, 1973; Prawatrungruang, 2002). Jäppinen (2010) recommends promoting and developing networking at an international level (across Europe in the case of the study that was analyzed) so that centers and teachers in different geographic areas can share methods and practices that have proven their effectiveness in reducing the number of dropouts.

Given that a large amount of responsibility regarding the students' success or failure falls on the teachers (Marín, Carmona, and Reche, 2014), there is a set of recommendations concerning the need to evaluate the teaching staff and improve the selection and hiring processes. In this regard, it is recommended that candidates' personal characteristics and competencies be evaluated and analyzed in order to hire the most well suited teachers (Cummins, 1973; Raffington, 2012; Marín, Carmona, and Reche, 2014). It is also recommended that those in charge of hiring the teachers take on the responsibility to contract educators who are committed to their profession and the success of students (Thaniel, 1989), as dedicated teachers play a significant role in reducing school leaving rates (Cadena, 2013).

Finally, Langley (1993), with the objective of creating more successful programs, discusses the utility of having teachers take on a more active role in the design and development of the vocational education programs as well as in the selection of students.

Recommendations concerning the advising and counseling of students (resources, time, content, placement, early identification, supervision, work placement, etc.)

The first subset of recommendations in this category refers to the need to increase investments in human resources so as to improve and enhance guidance counseling 
services (Tien, 1978; Aguirre, 1991). Along this line recommendations include hiring more psychologists, counselors, and social workers to work alongside the teaching staff in education centers (Klinger, 1973; Thaniel, 1989; Mohd Kamalludeen, 2012) as well as people in charge of following-up with students and helping them find jobs (Cummins, 1973).

Another set of measures aimed at reducing the number of vocational education dropouts deals with the need to hold guidance counseling sessions with students before they choose which training programs they wish to study (Wade, 1974; Langley, 1993; Mohd Kamalludeen, 2012). Similarly, some authors recommend that it would be useful to clearly inform students about possible training programs and subsequent job opportunities from an early age, especially for students at risk of dropping out (Aguirre, 1991; Rahona, 2012).

Related to these two subcategories, another set of recommendations refers to the content that this guidance should provide. It is suggested that it should serve to improve training- and job-related decision making processes so that students feel like agents able to influence their own professional careers and futures (Dykeman, 1977). Furthermore, they should empower students to make better decisions and have more self-control so that they are able to set realistic goals and make the necessary effort to reach them (Diamond, 2007; Mohd Kamalludeen, 2012). The literature we analyzed highlights the need to make students aware of the various post-secondary training options and career paths available (Tien, 1978; Diamond, 2007; Mohd Kamalludeen, 2012), and it suggests that students should be provided with information and knowledge about the working world, professions, job opportunities, and the characteristics of the jobs that are associated with each training program (Wade, 1974; Colding, 2006; Raffington, 2012).

Other recommendations along this same line have to do with the need to include elements in the training programs related to actively searching for jobs. This would improve students' basic job searching abilities such as writing cover letters, responding to job offers, creating résumés, and being prepared for job interviews (Dykeman, 1977; Raffington, 2012).

Another set of recommendations for reducing the number of dropouts is focused on the need to improve the process of assigning students to training programs that line up with their interests and needs. In this respect, it is suggested that greater effort should be made to guarantee that students have access to the courses that they chose as their first option (Azzarano, 1981) and that students have a previous interest, bond, or experience with the professions for which they will be trained (Diamond, 2007; Elffers, Oort, and Karsten, 2012). It is also recommended that the teaching staff take a more central role, not only in the design and implementation of the training programs, but also in the selection of students (Langley, 1993) even though some authors recommend increasing available resources and contracting people specifically in charge of identifying students' needs, interests, and abilities in order to guide them toward programs and courses that are suited to their characteristics (Cummins, 1973; Beekhoven and Dekkers, 2004; Diamond, 2007; Mohd Kamalludeen, 2012).

Related to this is another subcategory dealing with the establishment of evaluation systems for the on time identification of students who are risk of dropping out (Tien, 
1978; Thaniel, 1989; Diamond, 2007; Fanoiki, 2014) in order to intervene as soon as possible and thus better attend to students' needs (Tien, 1978), provide students with specialized and personalized guidance (Klinger, 1973; Wade, 1974), and avoid the dropout until the student acquires adequate levels of professional competencies and/or finishes his/her studies (Klinger, 1973; Rogers, 2001).

To this end, some recommendations refer to the usefulness of improving records and systems for gathering information about students. Cummins (1973) and Raffington (2012) suggest creating records with data on each student who enrolls. And others suggest coming up with early warning indicators (Fanoiki, 2014) that provide counselors and teachers with information that allows them to identify students' needs on time (Diamond, 2007; Mohd Kamalludeen, 2012). Diamond (2007) also recommends evaluating students' academic and family backgrounds. This could be done with an identification system that uses questionnaires that could be given to first year (Tien, 1978) or newly enrolled (Klinger, 1973) students, and it would be especially useful for students coming from other centers (Diamond, 2007). The use of strategies involving individualized qualitative monitoring, such as follow-up interviews, meetings with parents, etc. is also recommended (Diamond, 2007).

Another set of recommendations refers to the need to be responsible for providing students with job placement services. In this regard, it would be useful for programs to create mentoring schemes that follow specific guidelines (Raffington, 2012), hire personnel and counsellors to be in charge of work placements (Cummins, 1973), and find career opportunities in the local community (Raffington, 2012).

Finally, this category includes suggestions that aim to improve the monitoring of student successes and failures after completing their training. In this respect, hiring personnel to carry out this monitoring is recommended (Cummins, 1973; Cadena, 2013; Taş, Bora, Selvitopu, and Demirkaya, 2013), as is the creation of organized data systems with the same end (Cummins, 1973; Marín, Carmona, and Reche, 2014). Klinger (1973) and Portis (2013) also suggest coming up with indicators of success, e.g., the student retention rate, the graduation rate, and the placement rate.

\section{Conclusions and shortcomings}

This review improves upon previous work and fills a gap in the knowledge about the measures and strategies for reducing the number of dropouts in vocational education programs by summarizing the main suggestions stemming from previous research. The novelty of this article is that it can be used as a base from which to design and judge policies and practices for preventing school leaving in vocational training programs. However, the nature of the evidence that we have available and the limitations of this review should be taken with a grain of salt. No strong inferences should be drawn from the results of the analysis, and readers should take caution when interpreting and applying the conclusions of the review. The fact that we took studies from very different contexts (with respective differences in the vocational programs they analyzed and the dropout phenomenon itself) and considered them under the same lens should be noted. Furthermore, we grouped studies that aimed to analyze the effectiveness of various measures 
with studies that did not have this objective and rather suggested some ideas for how to face the problem of dropouts as a final thought, not as exacting precise measures. However, the rigorous nature of our methodology for searching for, finding, accessing, and analyzing documents, compensates for these shortcomings [which themselves are common in literature reviews in the field of education (Sureda and Comas 2017)].

The measures suggested in the literature that we analyzed in this paper are in line with those highlighted by Lehr et al. (2003) in their study based on 45 preventative and intervention measures for confronting school leaving in secondary education. These authors organized the strategies that were mentioned in the literature according to their objective, and they were focused on students (guidance programs, improving interpersonal relationships, improving the climate in the classroom, etc.), methodological aspects and teaching (improving individualized support, personalizing the educational process in cases with a greater risk of dropout, making the education more flexible, etc.), and improving the culture and organizational aspects within education centers as well as centers' relationships with the community.

There is a certain level of consensus regarding the fact that successful interventions in vocational education programs do more than increase student attendance, rather they help students and families who feel marginalized from teachers and classmates to connect with the school and the learning process (Salva-Mut et al. 2014). Student participation throughout their academic careers depends, in large part, on the alignment of the school environment with students' characteristics, which can enable students to be able to handle academic demands. One of the main conclusions of our review revolves around this point: the recurring idea in many papers about the importance of "personalizing" education in order to prevent dropouts. This means that understanding the nature of the academic, social, and personal problems affecting students and adapting services to individual concerns is essential to fight against early school leaving.

The recommendations that came up during this literature analysis highlight the need to establish and cultivate positive relationships between students and their teachers, parents, and peers as well as carry out systematic monitoring of students' progress throughout the training programs. Students must also be given the opportunity to succeed in academics, their problem solving skills must be strengthened, and an environment must be created that encourages support (especially with respect to helping at-risk students confront personal problems) and conveys the importance of education for students' future personal and professional success. The fact of the matter is that the majority of the focus is on measures or recommendations that address students (improving guidance, monitoring, personalization, access to jobs, etc.); there are many less measures that 
focus on the teachers. By doing this, we are in some way putting the blame on students and absolving teachers and institutions from blame.

We wish to close this paper by highlighting the need to increase and improve the research (systematically and rigorously) that focuses on which intervention measures and strategies are the most appropriate and effective for combating the high number of dropouts seen in vocational education programs, and therefore promote the design of robust and successful policies and interventions. Our contribution could be a good starting point.

Authors' contributions

All three authors have contributed in an equal basis to all the process of conducting the literature review, analysis and process of data and writing the article. All authors read and approved the final manuscript.

Author details

${ }^{1}$ Department of Applied Pedagogy and Psychology of Education, Balearic Islands University (Spain), Campus UIB Building Cifre de Colonya Office REDINED, 07122 Palma de Mallorca, Spain. ${ }^{2}$ Department of Applied Pedagogy and Psychology of Education, Balearic Islands University (Spain), Campus UIB Building Beatriu de Pinos Office 16, 07122 Palma de Mallorca, Spain. ${ }^{3}$ Department of Applied Pedagogy and Psychology of Education, Balearic Islands University (Spain), Campus UIB Building Anselm Turmeda Office D185, 07122 Palma de Mallorca, Spain.

Acknowledgements

Not applicable.

Competing interests

The authors declare that they have no competing interests.

Availability of data and materials

The data are provided by the authors on request.

Consent for publication

Not applicable.

Ethics approval and consent to participate

Not applicable.

Funding

This article is part of the activities of the research project, funded by the Spanish Ministry of Economy and Competitiveness, entitled "Success and dropout pathways in vocational education and training in Spain" (with reference EDU2013-42854-R).

\section{Appendix}

See Table 3. 


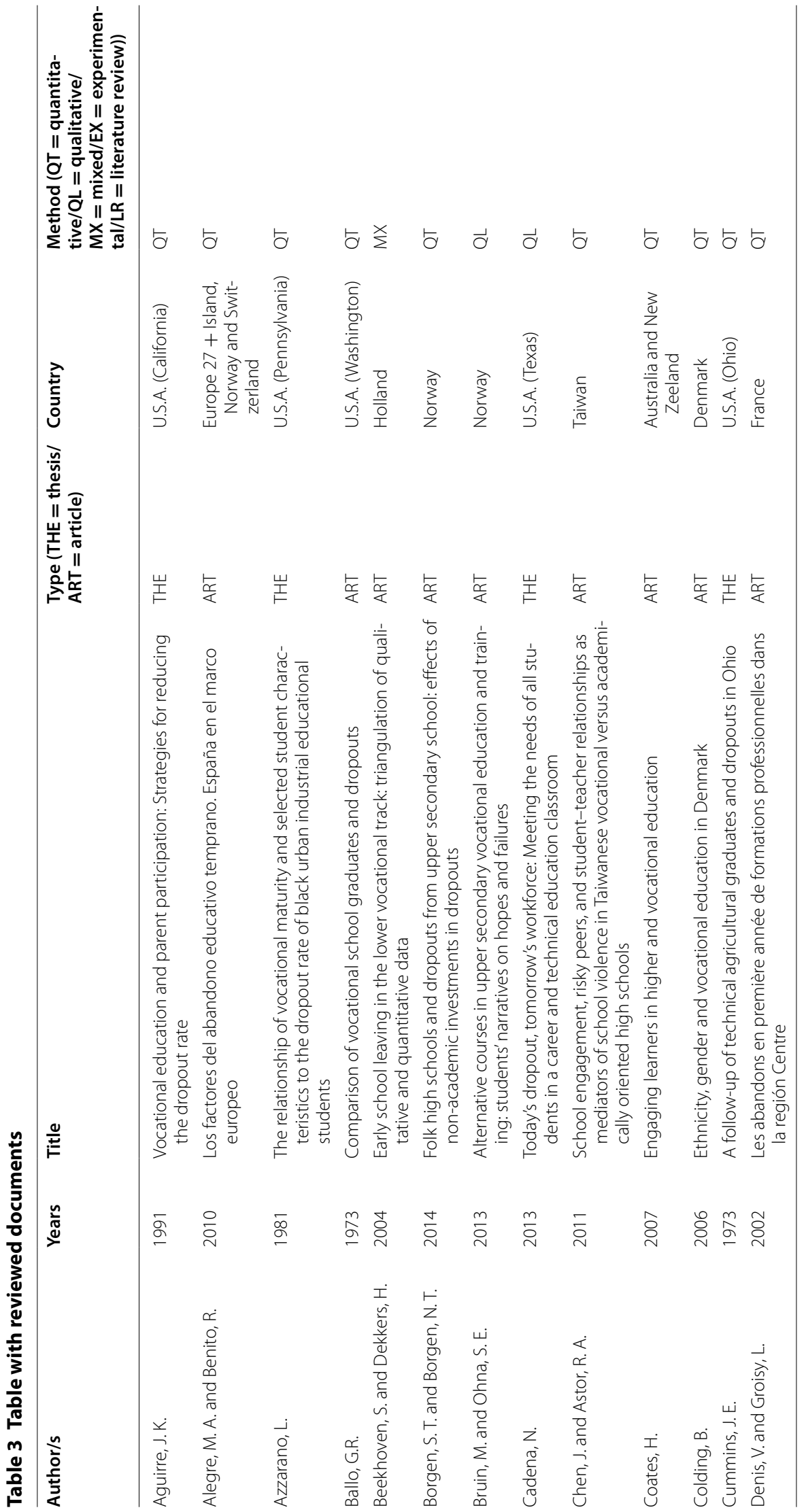




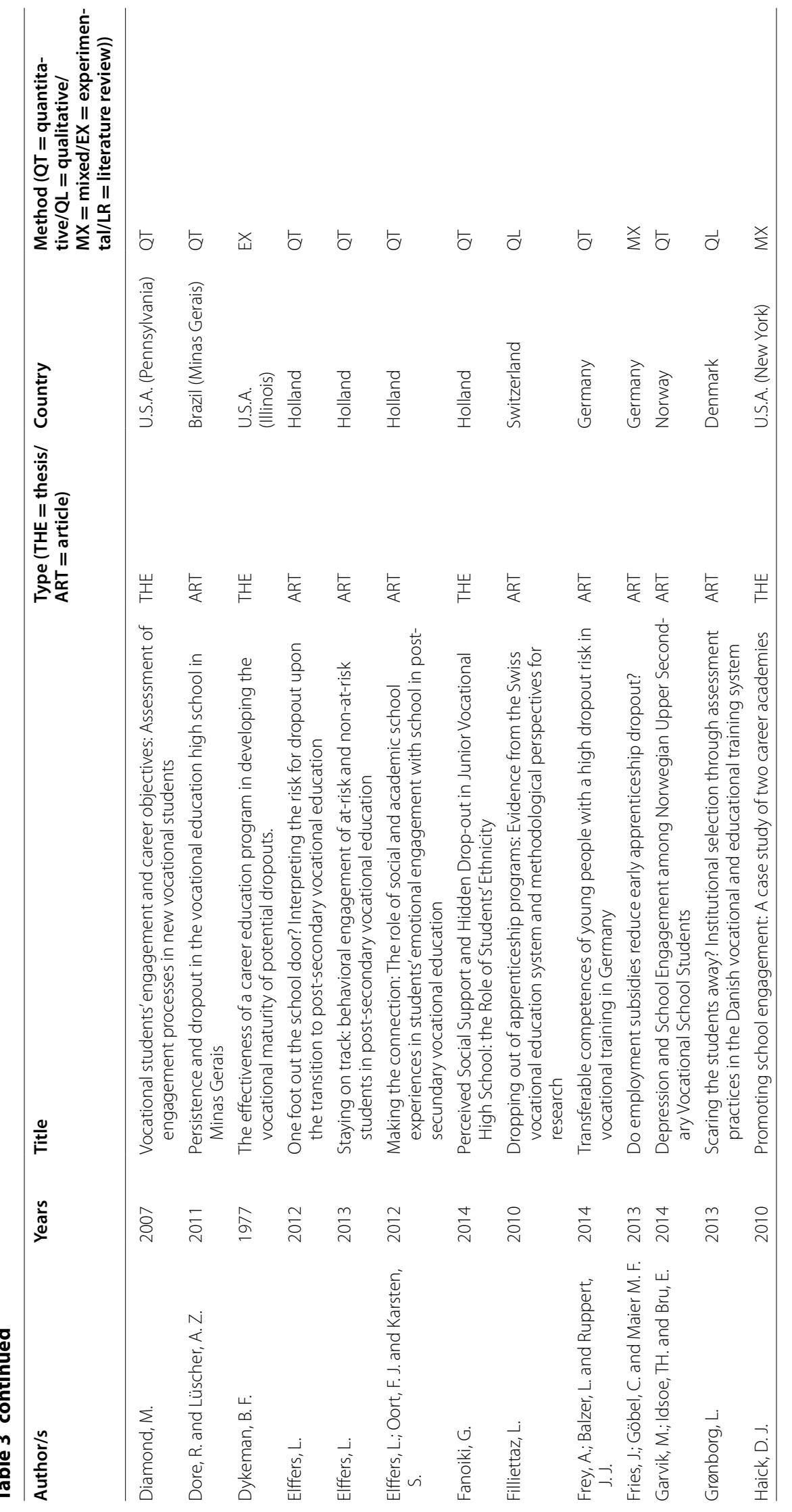




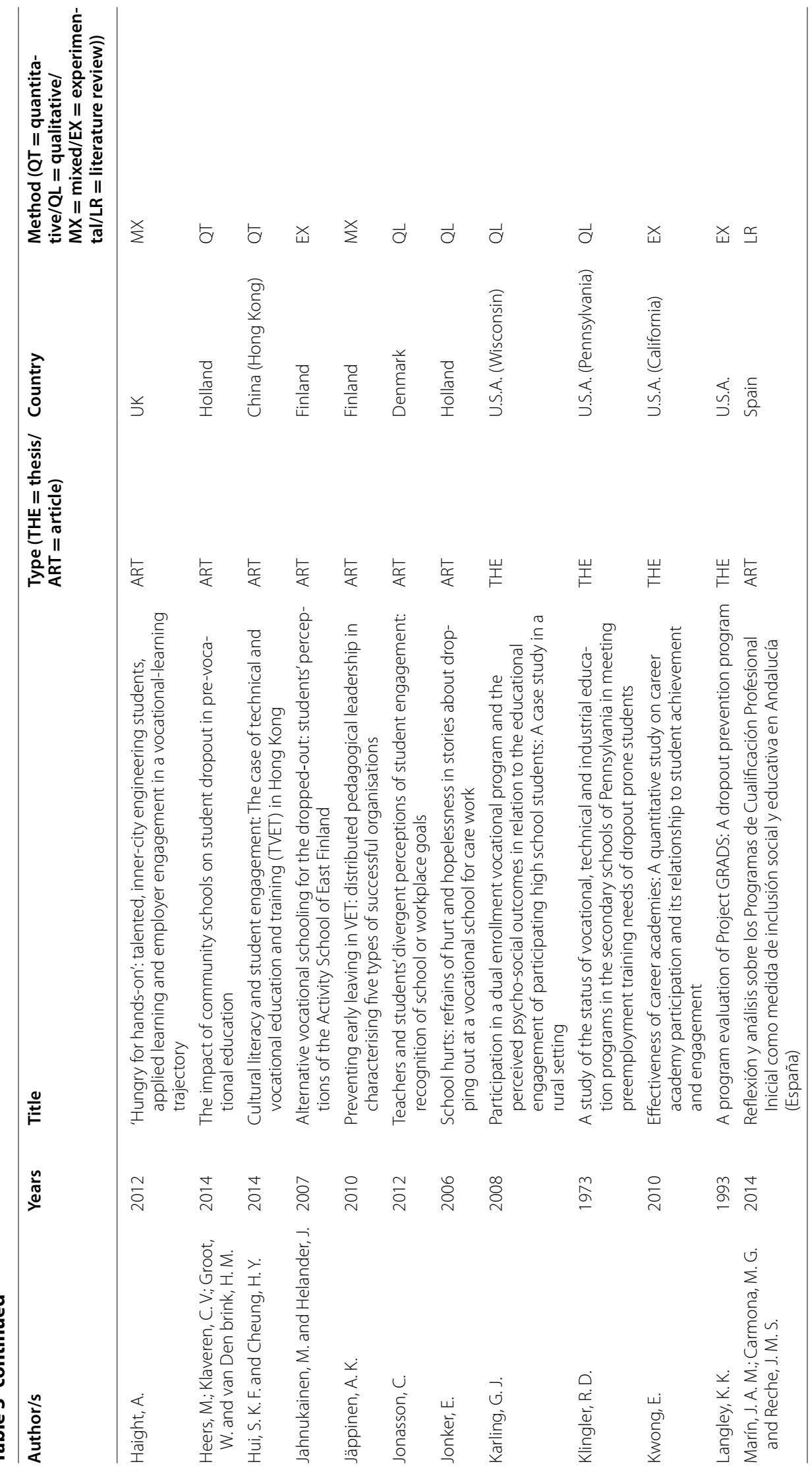




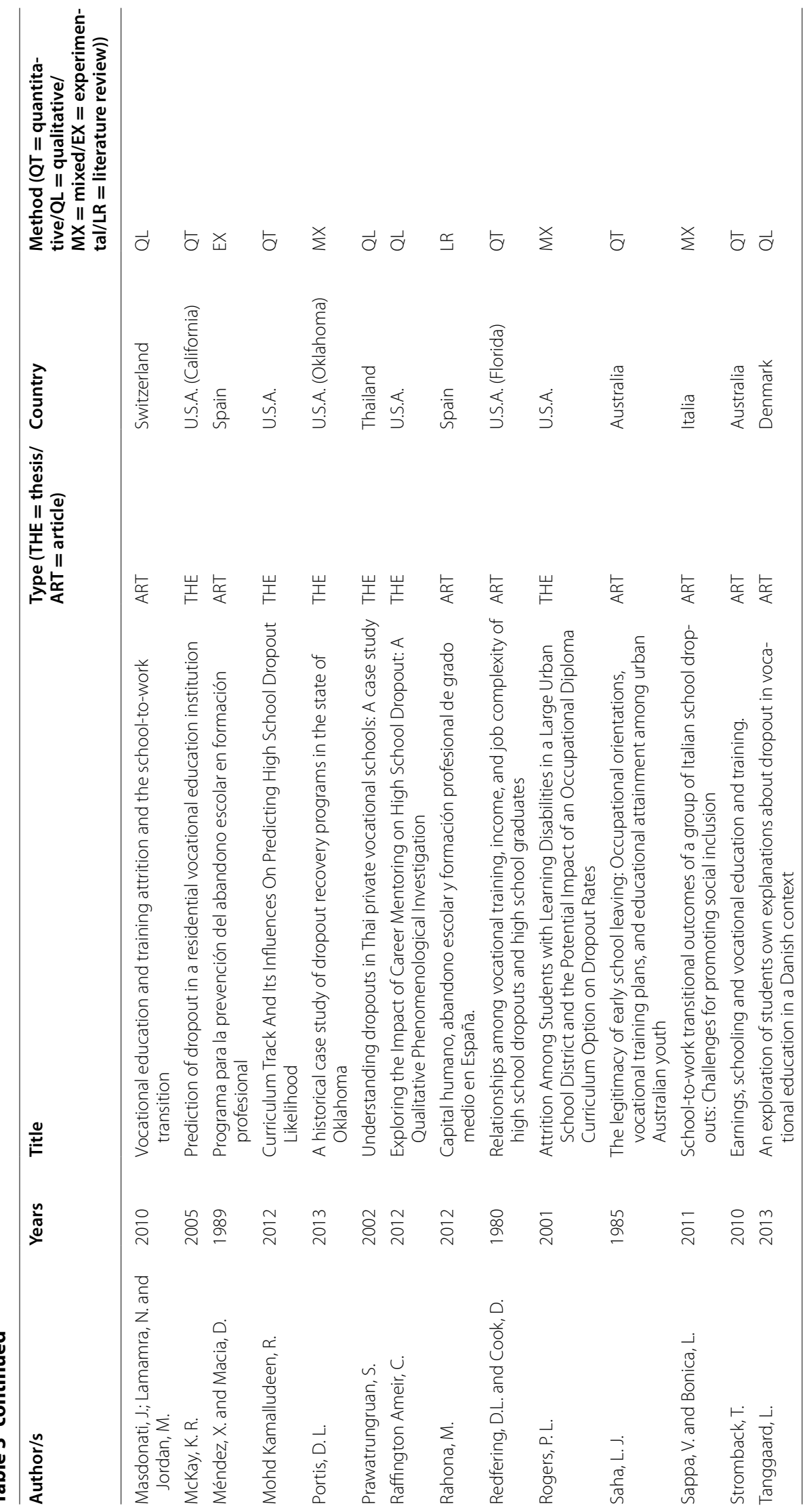




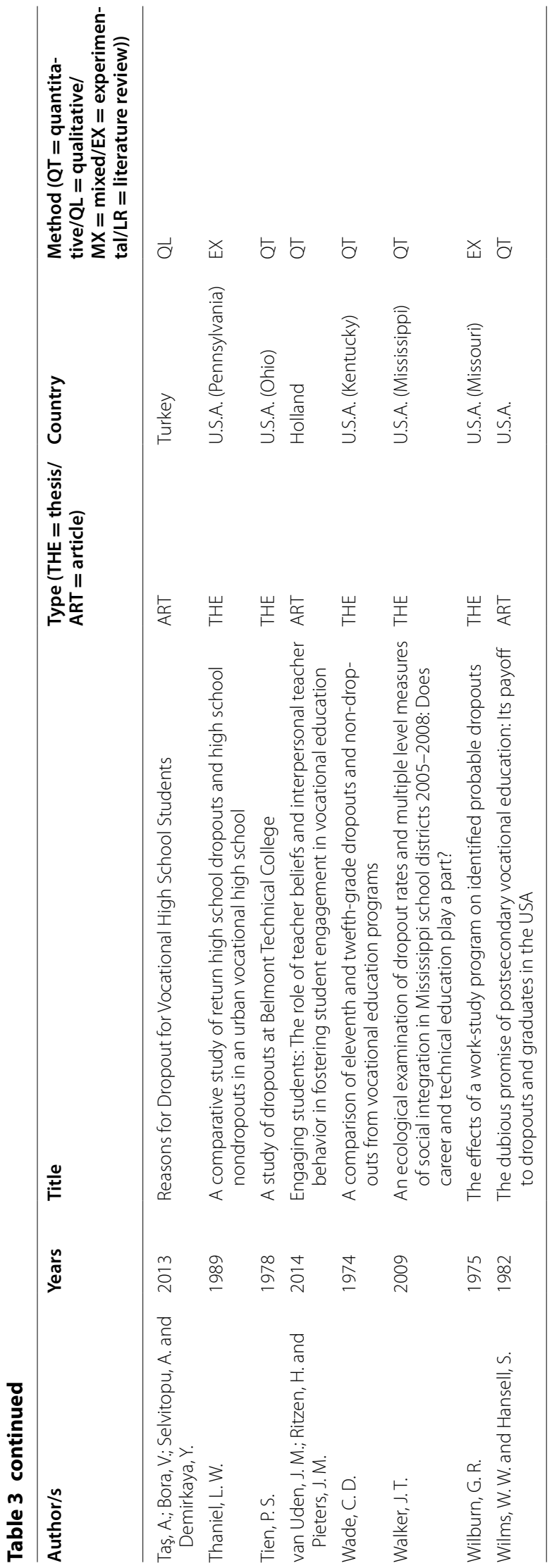




\section{Publisher's Note}

Springer Nature remains neutral with regard to jurisdictional claims in published maps and institutional affiliations.

Received: 23 March 2017 Accepted: 30 November 2017

Published online: 14 December 2017

\section{References}

Christenson SL, Sinclair MF, Lehr CA, Godber Y (2001) Promoting successful school completion: critical conceptual and methodological guidelines. Sch Psychol Q 16:468-484

De Wittea K, Cabusa S, Thyssena G, Groota W, van den Brinka U (2013) A critical review of the literature on school dropout. Educ Res Rev 10:13-28. https://doi.org/10.1016/j.edurev.2013.05.002

Dore R, Lüscher A (2011) Persistence and dropout in the vocational education high school in Minas Gerais. Cadernos de Pesquisa 41(144):770-789

European Commission (2011) Tackling early school leaving: a key contribution to the Europe 2020 Agenda. http://eur-lex europa.eu/legal-content/EN/TXT/HTML/?uri=CELEX:52011DC0018\&from=EN. Accessed 26 Feb 2017

Fink A (2005) Conducting research literature reviews. From the internet to paper. SAGE, London

Higgins JPT, Green S, editors (2011) Cochrane handbook for systematic reviews of interventions version 5.1.0. The Cochrane Collaboration, 2011. http://www.cochrane-handbook.org. Accessed on Mar 2011

Hovdhaugen E, Kottmann A, Thomas L (2015) Dropout and completion in higher education in Europe. Luxembourg: publications office of the European Union. http://ec.europa.eu/education/library/study/2015/annex-1-literaturereview en.pdf. Accessed 26 Feb 2017

Lehr CA, Hanson A, Sinclair MF, Christenson SL (2003) Moving beyond dropout prevention towards school completion: an integrative review of data-based interventions. Sch Psychol Rev 32:342-364

Littell JH, Corcoran J, Pillai V (2008) Systematic reviews and meta-analysis. Oxford University Press, New York

Mejía Navarrete L (2011) Problemas centrales del análisis de datos cualitativos. Revista Latinoamericana de Metodología de la Investigación Social 1:47-60

Moher D, Liberati A, Tetzlaff J, Altman DG, The PRISMA Group (2009) Preferred reporting items for systematic reviews and meta-analyses: the PRISMA statement. PLoS Med. https://doi.org/10.1371/journal.pmed1000097

Petticrew M, Roberts H (2006) Systematic reviews in the social sciences. A practical guide. Blackwell Publishing, Oxford Salva-Mut F, Oliver-Trobat MF, Comas-Forgas R (2014) Abandono escolar y desvinculación de la escuela: perspectiva del alumnado. Magis. Revista Internacional de Investigación En Educación. https://doi.org/10.11144/javeriana.m6-13. aede

Strauss A (1987) Qualitative analysis for social scientist. Cambridge University Press, Cambridge

Strauss A, Corbin J (1998) Basics of qualitative research. Techniques and procedures for developing grounded theory. SAGE, London

Sureda-Negre J, Comas-Forgas R (2017) La revisión bibliográfica desde una perspectiva sistemática. In: Pantoja Rendón S, Angulo Rasco JF (eds) La investigación cualitativa. GLEM, Buenos Aires

Tanggaard L (2013) An exploration of students' own explanations about dropout in vocational education in a Danish context. J Vocat Educ Train. https://doi.org/10.1080/13636820.2013.834956

Taylor SJ, Bogdan R (1987) Introducción a los métodos cualitativos de investigación. La búsqueda de significados. Paidós, Barcelona

U.S. General Accounting Office (2002) School dropouts: education could play a stronger role in identifying and disseminating promising prevention strategies. U.S. General Accounting Office, Washington

\section{Submit your manuscript to a SpringerOpen ${ }^{\circ}$ journal and benefit from:}

- Convenient online submission

- Rigorous peer review

- Open access: articles freely available online

- High visibility within the field

- Retaining the copyright to your article

Submit your next manuscript at $\boldsymbol{\nabla}$ springeropen.com 